\title{
Infiltración vesical por leucemia linfoblástica aguda. A propósito de un caso y revisión de la literatura
}

\author{
Martín Hernández M, Alonso y Gregorio S, Cansino Alcaide R, Pérez-Utrilla M, Aguilera Bazán A, \\ Regojo Zapata R*, De la Peña Barthel JJ.
}

Servicio de Urología. *Servicio de Anatomía Patológica. Hospital Universitario La Paz, Madrid.

Actas Urol Esp. 2008;32(5):563-566

\section{RESUMEN}

INFILTRACIÓN VESICAL POR LEUCEMIA LINFOBLÁSTICA AGUDA. A PROPÓSITO DE UN CASO Y REVISIÓN DE LA LITERATURA

Exponemos el caso de un paciente con infiltración vesical por Leucemia Aguda Linfoblástica.

Debido a lo infrecuente de su presentación, revisamos la literatura publicada hasta el momento encontrando 14 casos desde 1932. Aunque excepcional, en un paciente que presenta hematuria de novo o repetida y ha tenido como antecedentes alguna enfermedad hematológica, debemos pensar en la infiltración vesical por la leucemia como posible diagnóstico diferencial.

Palabras clave: Infiltración. Leucemia. Hematuria. Vejiga.

\section{ABSTRACT}

LEUKEMIC INFILTRATION OF THE URINARY BLADDER. A NEW CASE AND LITERATURE REVIEW

We expose you one case of leukemic infiltration of the urinary bladder.

This kind of infiltration is rare so we reviewed the literature finding 14 cases since 1932. Although this hematological infiltration is very unusual, it should be considered in patients with leukemia and hematuria.

Keywords: Infiltration. Leukemia. Hematuria. Bladder.

$\mathrm{L}$ a primera referencia publicada de afectación vesical por Leucemia Aguda (tanto linfoblástica como mieloblástica) fue en 1932. Se han descrito y publicado hasta la fecha 14 casos en la literatura.

En general es más frecuente en la edad infantil, a diferencia de nuestro caso, con hematuria como síntoma más característico y con un pronóstico desfavorable.

La finalidad de éste artículo es recordar que este tipo de enfermedades hematológicas pueden manifestarse metastasicamente en la vejiga así como hacer una revisión de la literatura acerca de ésta patología.

\section{ANAMNESIS}

Mujer de 76 años con antecedentes personales de alergia a la penicilina, HTA en tratamiento con IECAs, hipercolesterolemia, glaucoma en tratamien- to médico, Fiebre de Malta en la infancia, leucemia aguda linfoblástica $\mathrm{B}$ común en teórica remisión completa diagnosticada en 1999, hernia de hiato, colelitiasis y Timpanoplastia en 1997. No presenta antecedentes familiares de interés.

La paciente es estudiada por el Servicio de Ginecología por presentar metrorragia postmenopaúsica, incontinencia de orina de 4 compresas al día, episodios de hematuria aislada y ocasional tenesmo vesical. Igualmente presenta astenia, anorexia y pérdida de $8 \mathrm{~kg}$ de peso en los últimos dos meses.

Se realizó una ecografía ginecológica en la que se informó de un útero en anteversión de 5,7x2,1 cm con endometrio de $6 \mathrm{~mm}$ y endocérvix con algunas formaciones quísticas. Vejiga con paredes engrosadas de bordes irregulares.

Ante los hallazgos ecográficos la paciente pasó a nuestras consultas para continuar con el estudio. 


\section{EXPLORACIÓN FÍSICA Y ANALÍTICA}

La exploración física denotaba astenia y anorexia con pérdida de peso en los últimos meses. El resto fue rigurosamente normal, no se observó colpocele ni cistocele y el Test de Booney-Marshall resultó positivo.

El análisis de sangre mostraba:

- Hemograma: Hemoglobina: 10,2 g/dl, Hematocrito: 29\%, Leucocitos: 5500 (neutrófilos: 44,5\%, linfocitos: 52\%, monocitos: 1,9\%), VSG: 82 , resto normal.

- Bioquímica: Creatinina: 1,8, LDH: 606, Urea: 98 resto de parámetros normales.

- Coagulación: normal.

- Sistemático de orina: proteinuria y Leucocituria + +

\section{OTRAS EXPLORACIONES COMPLEMENTARIAS}

- Citología de orina negativa para células tumorales malignas.

- Urocultivo: se aísla E. Coli. (>10.000 UFC) BK negativo.

- Cistoscopia: se observa una neoformación vesical bullosa y mamelonada localizada en cuello, base y trígono.

- Estudio urodinámico: sugestivo de incontinencia mixta.

\section{TÉCNICAS DE IMAGEN}

Se solicitó la realización de una Ecografía abdominal y de una Urografía intravenosa para estudiar el tracto urinario superior ante los hallazgos de la cistoscopia. En la ecografía se observó que el hígado y la vía biliar eran normales. La vesícula biliar presentaba imágenes hiperecogénicas con sombra acústica posterior compatibles con colelitiasis. El páncreas y el bazo eran normales. Quistes parapiélicos renales bilaterales con acusada ectasia pielocalicial en el riñón derecho y moderada hidronefrosis renal izquierda. Vejiga sin hallazgos ecográficos valorables.

En la Urografía intravenosa: se observaba un retardo bilateral de la eliminación del contraste, con dilatación de ambas vías excretoras, con punto de partida de la dilatación a nivel de los uréteres yuxtavesicales en los que se podía ver un filamento de los mismos.

No fue posible valorar la vejiga debido a la escasa plenificación vesical con contraste, por la incon- tinencia que presentaba la paciente, por lo que para su valoración se recomendó realizar una cistografía.

\section{PROCEDIMIENTOS DIAGNÓSTICO- TERAPEÚTICOS}

Debido a la uropatía obstructiva bilateral que la paciente presentaba se practicó derivación urinaria mediante nefrostomías percutáneas bilaterales debido a la imposibilidad de cateterismo ureteral. Al mismo tiempo, se realizó una pielografía anterograda por las nefrostomías (Fig. 1) con placas miccionales tardías para poder valorar y completar el estudio vesical. En éste, se observaron además de una ureterohidronefrosis bilateral con punto de partida yuxtavesical, mínimos defectos de replección en ambas caras laterales de la vejiga (sobre todo en la izquierda) que no parecían rectificar la pared.

Una vez ingresada la paciente en el Servicio de Urología, se le practicó bajo anestesia intradural, Resección Transuretral de neoformación vesical con toma de biopsias aleatorias. El tacto bimanual era un T4 sugerente de pelvis congelada con la

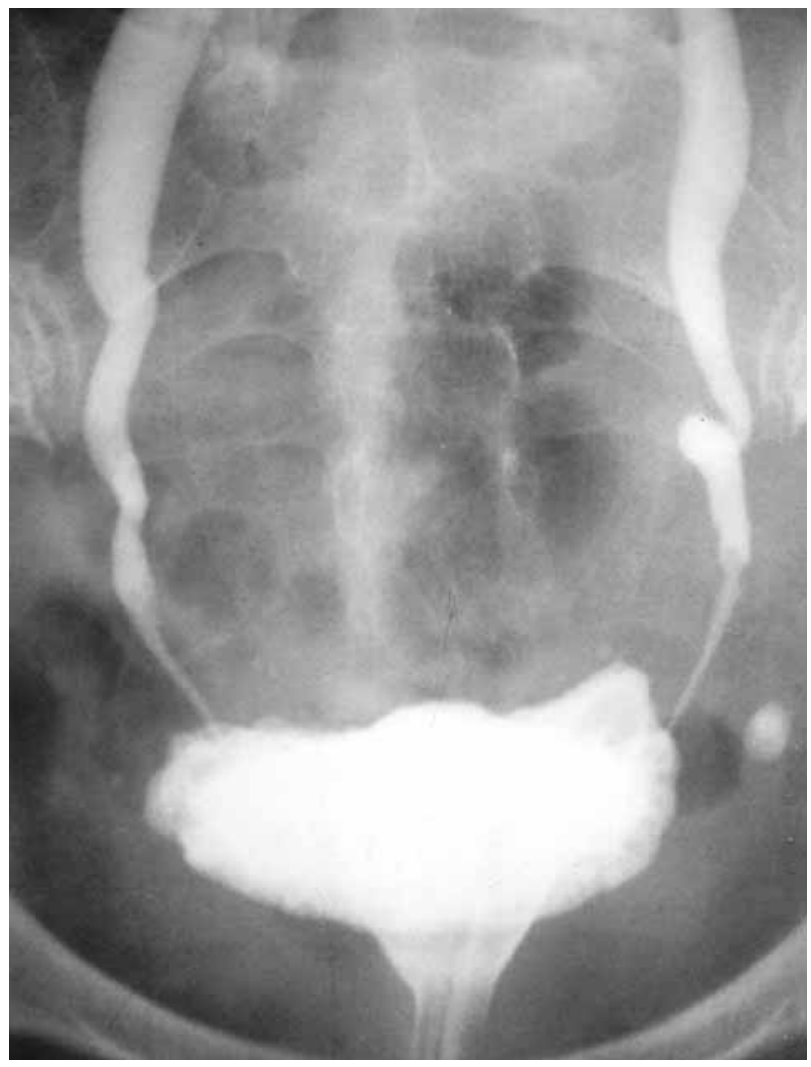

FIGURA 1. Véanse los defectos de replección en las caras laterales. 
visualización de una masa trigonal que se extendía a ambas caras laterales y fondo vesical. $\mathrm{El}$ aspecto macroscópico durante la resección era de infiltración de la capa muscular.

\section{ANATOMÍA PATOLÓGICA}

En las muestras de la resección transuretral se identificaron todas las capas de la vejiga, incluyendo tejido adiposo perivesical con una infiltración tumoral de patrón difuso en todas ellas, respetando en ocasiones el urotelio de superficie (Fig. 2). Las células tumorales eran de estirpe linfoide de mediano tamaño y elevada relación nucleocitoplasmática, escaso citoplasma y núcleos hipercromáticos, sin nucleolos y con frecuentes figuras de mitosis. Las técnicas de inmunohistoquímica (Fig. 3) demostraron positividad en las células tumorales de Tdt y CD10, no evidenciándose presencia de CD20, CD3 ni CD5. El índice de proliferación con Mib-1 era del 40\%. Mediante PCR se realizó reordenamiento $\mathrm{IgH}$ y TCR gamma que fueron negativos.

\section{DIAGNÓSTICO FINAL}

El diagnóstico, por lo tanto, fue de infiltración de pared vesical y tejido fibroadiposo perivesical por una leucemia linfoblástica aguda.

\section{EVOLUCIÓN}

Posteriormente, se completó el estudio de extensión con un TAC abdómino-pélvico (Fig. 4) que informaba de la existencia de una masa a nivel de pelvis

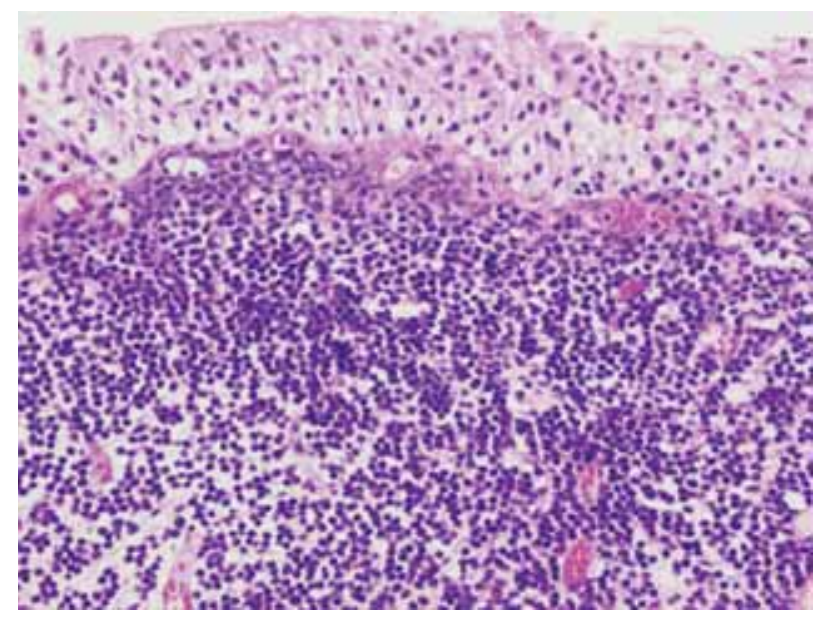

FIGURA 2. (Hematoxilina eosina) Infiltración tumoral respetando áreas de urotelio.

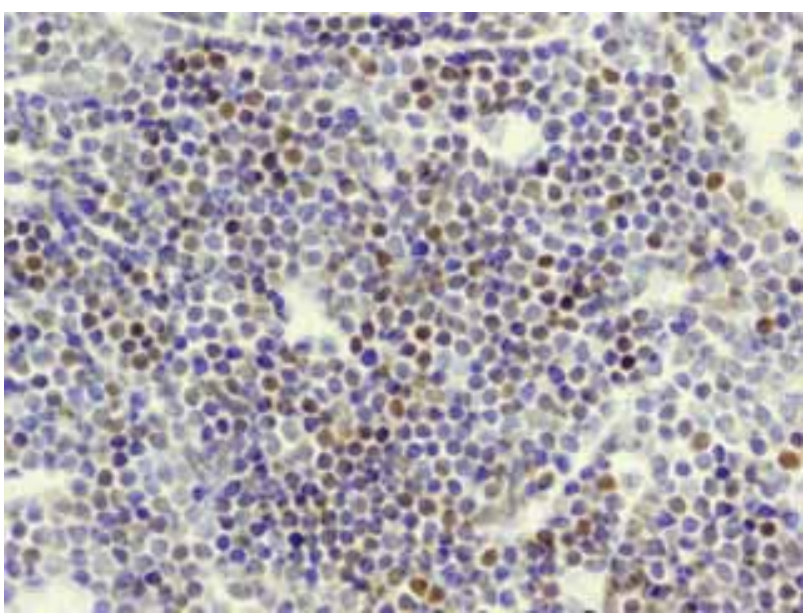

FIGURA 3. Técnicas de inmunohistoquimica con positividad para células Tdt.

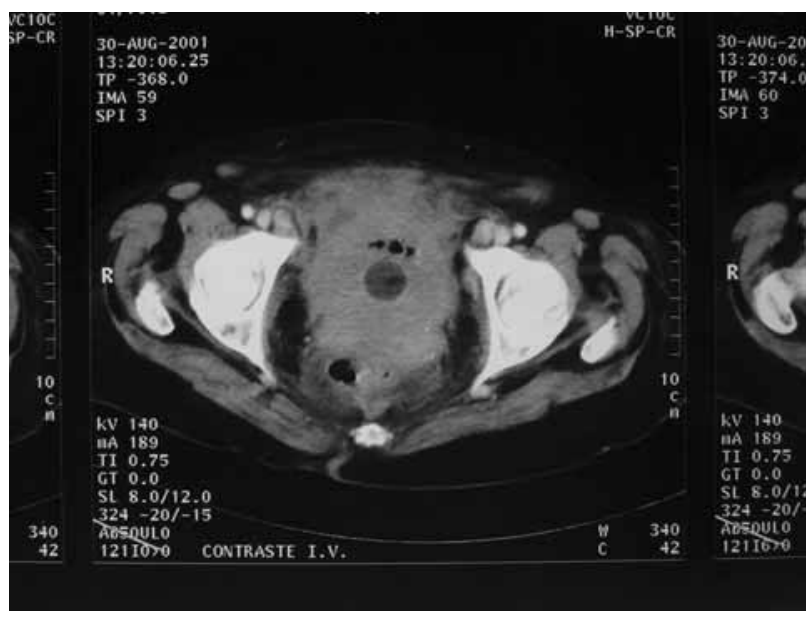

FIGURA 4. TAC abdomino-pélvico. Ocupación vesical por neoformación y desplazamiento del recto. Adenomegalias.

menor, que infiltraba vejiga y tejido celular subcutáneo con desplazamiento de recto. Importante conglomerado adenopático retroperitoneal que llegaba hasta iliacas comunes y obturatriz izquierda además de adenomegalias inguinales bilaterales profundas y superficiales.

Ante estos hallazgos y el resultado anatomopatológico de las biopsias vesicales, la paciente fue remitida al Servicio de Hematología para tratamiento quimioterápico con vincristina, daunorubicina, asparraginasa y prednisona. Las cifras de bilirrubina, fosfatasa alcalina, GGT y creatinina aumentaron de forma considerable en los días posteriores. A la semana, la paciente comenzó con mal estado general y deterioro progresivo, falleciendo poco tiempo después. 


\section{DISCUSIÓN}

La infiltración leucemoide en las vías excretoras es un hecho raro en la práctica clínica diaria, aunque no lo es tanto en las autopsias. La afectación vesical es, todavía, un evento aún más infrecuente ${ }^{1}$. Kirshbaum and Preus ${ }^{2}$ obtuvieron enfermedad leucémica en el riñón en 78 casos de 123 autopsias y sólo un caso de infiltración en vejiga. Watson et $\mathrm{al}^{3}$ estudiaron 234 casos de leucemia en los que no encontraron ni un solo caso de infiltración vesical.

Se ha revisado la literatura al respecto y se han encontrado un total de 14 casos publicados desde el año 1932 hasta 2002. En 8 pacientes la infiltración fue por una Leucemia Linfática Aguda, en 2 por una Leucemia Mieloide Aguda y en 4 de los pacientes no se pudo determinar de qué tipo de leucemia se trataba. En 5 de los casos el diagnóstico fue postmortem.

El rango de edad se encontraba entre los 9 meses y los 81 años con predominio de los casos pediátricos con un total de 11 casos $^{4}$. La relación hombre-mujer fue de 2 a 1 .

El síntoma más frecuente fue la hematuria (10 casos) $)^{5,6}$; en segundo lugar la uropatía obstructiva silente con Insuficiencia Renal y en un solo caso incontinencia urinaria por infiltración de la uretra ${ }^{7}$. Cuando la hematuria aparece, en el diagnóstico diferencial se debe tener en cuenta la enfermedad hematológica. A continuación, las infecciones, la trombocitopenia o las coagulopatías, cistitis hemorrágica debida a ciclofosfamida o ifosfamida y otras entidades hematológicas como los linfomas.

Cuando se sospecha que la vejiga está infiltrada es aconsejable realizar, para estudiar el tracto urinario superior, una Ecografía, UIV o un TAC aunque el diagnóstico definitivo, nos lo dará el análisis anatomopatológico de la biopsia vesical.

Nuestra paciente presentaba episodios de hematuria aislada, metrorragia ocasional, e incontinencia de orina. Fue derivada desde el Servicio de Ginecología a nuestro servicio por encontrar en una ecografía la sospecha de neoformación vesical. La biopsia se realizó con el resultado anteriormente expuesto, siendo la evolución de la paciente desde aquel momento de deterioro generalizado hasta el éxitus.

Entre las posibilidades de tratamiento, están contempladas la quimioterapia, radioterapia, resección transuretral de vejiga y la cistectomía radical, aunque el tratamiento ideal de esta entidad aún es incierto. Lo que sí parece razonable, es que el tratamiento sea abordado conjuntamente por los oncohematólogos y los urólogos ${ }^{8}$.

En conclusión, todo paciente que tiene o ha tenido una enfermedad hematológica que se presenta con episodios de hematuria o incontinencia de orina a parte de los diagnósticos diferenciales mencionados, siempre hay que pensar en la extensión de una enfermedad hematológica.

\section{REFERENCIAS}

1. Dedic K. Hairy cell leucemia:an autopsy study. Acta Medica (Hradec Kralove). 2003;46(4):175-177.

2. Kirshbaum JD, Preuss FS. Leukemia. A clinical and pathologic study of one hundred and twenty-three fatal cases in a series of 14400 necropsies. Arch Intern Med. 1943;71:777.

3. Watson EM, Sauer HR, Sadugor MG. Manifestations of lymphoblastomas in the genito-urinary tract. J Urol. 1949;61(3):626645.

4. Persky L, Newman AJ, Tucker AS. Urologic manifestations of childhood leukaemia. J Urol. 1972;107(6):1073-1077.

5. Chang CY, Chiou TJ, Hsieh YL, Cheng SN. Leukemic infiltration of the urinary bladder presenting as uncontrollable gross hematuria in a child with acute lymphoblastic leukemia J Pediatr Hematol Oncol. 2003;25(9):735-739.

6. Troup CW, Thatcher G, Hodgson NB. Infiltrative lesion of the bladder presenting as gross hematuria in child with leukaemia: case report. J Urol. 1972;107(2):314-315.

7. Tribedi BP, Banerjee SK. An unusual manifestation of lymphatic leukaemia. J Indian Med Assoc. 1943;12:139.

8. Russo P. Urologic emergencies in the cancer patient. Semin Oncol. 2000;27(3):284-298.

Correspondencia autor: Dr. M. Martín Hernández

Servicio de Urología Hospital Univ. La Paz

$\mathrm{P}^{\circ}$ de la Castellana, 261 - 28046 Madrid. Tel: 917277000

E-mail: mariomhdez@yahoo.es

Información artículo: Nota clínica

Trabajo recibido: noviembre 2006

Trabajo aceptado: diciembre 2006 